Article

\title{
Isolation and Taxonomic Identity of Bacteriocin-Producing Lactic Acid Bacteria from Retail Foods and Animal Sources
}

\author{
Chris Henning 1,2,†, Paul Vijayakumar ${ }^{1,2, \dagger}$, Raj Adhikari ${ }^{1,2, \dagger}$, Badrinath Jagannathan 1,2,†, \\ Dhiraj Gautam $^{2, \dagger}$ and Peter M. Muriana ${ }^{1,2, \uparrow, *}$
}

1 Department of Animal Science, Oklahoma State University, Monroe Street, Stillwater, OK 74078, USA; E-Mails: cdhenni@okstate.edu (C.H.); paulpv@okstate.edu (P.V.); rajba@okstate.edu (R.A.); vengara@okstate.edu (B.J.)

2 Robert M. Kerr Food \& Agricultural Products Centre, Oklahoma State University, 109 FAPC Building, Monroe Street, Stillwater, OK 74078-6055, USA; E-Mail: dhiraj.gautam@okstate.edu

$\dagger$ These authors contributed equally to this work.

* Author to whom correspondence should be addressed; E-Mail: peter.muriana@okstate.edu; Tel.: +1-405-744-5563; Fax: +1-405-744-6313.

Academic Editor: Giuseppe Comi

Received: 30 January 2015 / Accepted: 9 March 2015 / Published: 19 March 2015

\begin{abstract}
Bacteriocin-producing $\left(\mathrm{Bac}^{+}\right)$lactic acid bacteria (LAB) were isolated from a variety of food products and animal sources. Samples were enriched in de Man, Rogosa, and Sharpe (MRS) Lactocilli broth and plated onto MRS agar plates using a "sandwich overlay" technique. Inhibitory activity was detected by the "deferred antagonism" indicator overlay method using Listeria monocytogenes as the primary indicator organism. Antimicrobial activity against $L$. monocytogenes was detected by 41 isolates obtained from 23 of 170 food samples (14\%) and 11 of 110 samples from animal sources (10\%) tested. Isolated $\mathrm{Bac}^{+} \mathrm{LAB}$ included Lactococcus lactis, Lactobacillus curvatus, Carnobacterium maltaromaticum, Leuconostoc mesenteroides, and Pediococcus acidilactici, as well as Enterococcus faecium, Enterococcus faecalis, Enterococcus hirae, and Enterococcus thailandicus. In addition to these, two Gram-negative bacteria were isolated (Serratia plymuthica, and Serratia ficaria) that demonstrated inhibitory activity against L. monocytogenes, Staphylococcus aureus, and Enterococcus faecalis (S. ficaria additionally showed activity against Salmonella Typhimurium). These data continue to demonstrate that despite more than a decade of antimicrobial interventions on meats and produce, a wide variety of food products still
\end{abstract}


contain $\mathrm{Bac}^{+}$microbiota that are likely eaten by consumers and may have application as natural food preservatives.

Keywords: lactic acid bacteria; bacteriocin; Listeria monocytogenes; food preservative

\section{Introduction}

Lactic acid bacteria (LAB) occur naturally on many retail foods and are often added as starter cultures in fermented products widely sold in the marketplace, such as cheese, yogurt, and buttermilk, while others are simply added as bacterial adjuncts, such as acidophilus milk or Bifidus yogurt [1,2]. Some of these organisms have gained notoriety for demonstrating a "probiotic" effect when ingested [3], while others are known for producing a variety of antimicrobials including lactic acid, hydrogen peroxide, bacteriophage, and bacteriocins which may be present in foods that are manufactured with them.

Bacteriocins are gene-encoded inhibitory proteins and those produced by Gram-positive LAB are inhibitory mainly to other Gram-positive bacteria. Some bacteriocins even display antagonistic activity towards Gram-positive foodborne pathogens and spoilage organisms [4,5]. Bacteriocins have varying inhibitory spectra and these properties allow for the development of applications towards roles in food safety or preventing spoilage $[4,6]$. They can also be used in tandem with other antimicrobial treatments (i.e., the hurdle effect) in order to enhance the preservation of food [7]. For example, the antimicrobial effect of nisin is enhanced when mixed with a metal chelating molecule like ethylenediaminetetraacetic acid (EDTA) or a pulsed-electric field which can increase its effectiveness towards Gram-negative bacteria [7]. Considering consumer's growing interest in natural products and the high cost of foodborne illness, food manufacturers are always looking for new ways to preserve food. The use of bacteriocins as natural antimicrobials may be one possible way to replace or enhance chemical preservatives $[3,5]$.

Lactic acid bacteria may be isolated from many sources as they are widely present in the environment and readily found on the surface of many raw food products and therefore are also found as surface environmental contaminants during food processing and consequently, even on processed foods. They are also present in the intestinal tracts of humans and animals and can therefore be found in feces which is generally considered one vehicle by which they are distributed onto field-grown crops and vegetables. During this study, we examined a variety of food and animal sources, screening for bacteriocin-producing lactic acid bacteria using Listeria monocytogenes as a primary indicator organism. Our intention was to identify bacteriocinogenic LAB that might have inhibitory activity against Gram-positive pathogens that could be applicable as food safety adjuncts for use as food preservatives.

\section{Experimental Section}

\subsection{Bacterial Cultures, Growth Conditions, and Storage}

De Man, Rogosa, and Sharpe Lactobacilli (MRS) broth (Difco Laboratories, Detroit, MI, USA) and agar were used to culture bacteriocin-producing $\left(\mathrm{Bac}^{+}\right)$lactic acid bacteria (LAB) when originally isolated from retail food or animal sources or when retrieved from our laboratory culture collection. Cultures were incubated overnight $(12-16 \mathrm{~h})$ at $30{ }^{\circ} \mathrm{C}$ by inoculating from an isolated colony, 
patch-plate smudge from an isolated colony, or a $1 \%$ inoculum from pure culture stocks or culture broths. L. monocytogenes 39-2 and Staphylococcus aureus ATCC 12600 were used as primary and secondary indicators for $\mathrm{Bac}^{+}$organisms, respectively, and were cultured in brain heart infusion media (BHI, Difco) [5,8]. Some $\mathrm{Bac}^{+}$strains were also tested for activity against E. coli O157:H7 ATCC 43890, Enterococcus faecalis ATCC 19433, and Salmonella Typhimurium H3380 that were cultured in tryptic soy broth (TS, Difco) before use. Master cultures were maintained by resuspending cell pellets in milkbased freezing media ( $11 \%$ non-fat dry milk powder, $1 \%$ glucose, $0.2 \%$ yeast extract) after centrifugation and stored frozen at $-80{ }^{\circ} \mathrm{C}$.

\subsection{Isolation of Bacteriocin-Producing $\left(\mathrm{Bac}^{+}\right)$LAB from Food and Animal Sources}

Food items were obtained from 4 local supermarkets in Stillwater, OK. These consisted of raw meat, fruit, vegetables, and herbs. In addition, beef cattle rumen, raw milk, and fecal samples were obtained from animals maintained by the Dept. of Animal Science, Oklahoma State University (Stillwater, OK, USA). Enrichment was performed in Whirl-Pak ${ }^{\circledR}$ filter bags (Nasco, Fort Atkinson, WI, USA) as a 10-fold dilution in MRS Broth (Difco) for $24 \mathrm{~h}$ (or $4 \mathrm{~h}$ ) at $30^{\circ} \mathrm{C}$. Enriched broth was serially diluted and spread plated onto buffered ( $\mathrm{pH} 7.4$ with $0.1 \mathrm{M}$ sodium phosphate dibasic and $8 \mathrm{mM}$ sodium phosphate monobasic) MRS agar plates (Figure 1). Plated samples were immediately covered with MRS agar (the sandwich layer) and incubated at $37^{\circ} \mathrm{C}$ for 12 to $48 \mathrm{~h}$. The sandwiched colonies were then overlaid with tempered molten "soft" MRS agar $(0.75 \%$ agar) inoculated with $1 \mathrm{~mL}$ of indicator organism (e.g., Listeria monocytogenes, $\sim 1 \times 10^{9} \mathrm{cfu} / \mathrm{mL}$ ) per $100 \mathrm{~mL}$ of molten media and again incubated at $37^{\circ} \mathrm{C}$ until the indicator lawn grew to completion. Bacteriocin-producing colonies were then isolated as described previously [9] and processed as depicted in Figure 1.

\subsection{Exclusion of Other Inhibitors}

The possibility that other inhibitors common to $\mathrm{LAB}$ may give inhibitory reactions appearing as bacteriocin activity were eliminated using the following assays [10-12].

Bacteriophage may demonstrate zones of inhibition when concentrated phage-containing preparations are spotted on a susceptible host (i.e., "confluent lysis"). When the bacteriophage-containing suspension is titered to extinction, individual plaques would be observed if inhibition zones were due to phage infection.

Hydrogen peroxide may be produced by some LAB and can be inhibitory to organisms (although L. monocytogenes is catalase-positive). The possibility of hydrogen peroxide activity was eliminated by addition of catalase as described previously, including control solutions of 3\% hydrogen peroxide [13].

Acid inhibition was eliminated from consideration by neutralizing spent culture supernatant fractions and/or buffering base agar/sandwich overlays with phosphate buffer during bacteriocin isolation and bacteriocin confirmation procedures. Control assays included cell-free culture supernatants from a bacteriocin-negative $\left(\mathrm{Bac}^{-}\right)$lactic acid-producing culture, Lb. delbrueckii 4797.

The application of protease to hydrolyze the protein content of bacteriocins and eliminate activity was examined by adding $20 \mu \mathrm{L}$ (i.e., $21 \mathrm{IU}$ ) of pronase E (1060 units/mL; Sigma cat. No. 42H0749) to $80 \mu \mathrm{L}$ of bacteriocin preparation, incubated at $30^{\circ} \mathrm{C}$ for $1 \mathrm{~h}$, and then spotted on indicator lawns to view presence/absence of bacteriocin activity. Control reactions used water instead of protease. 


\section{A. Detecting Bac+ Colonies from Food Samples (deferred antagonism assay)}

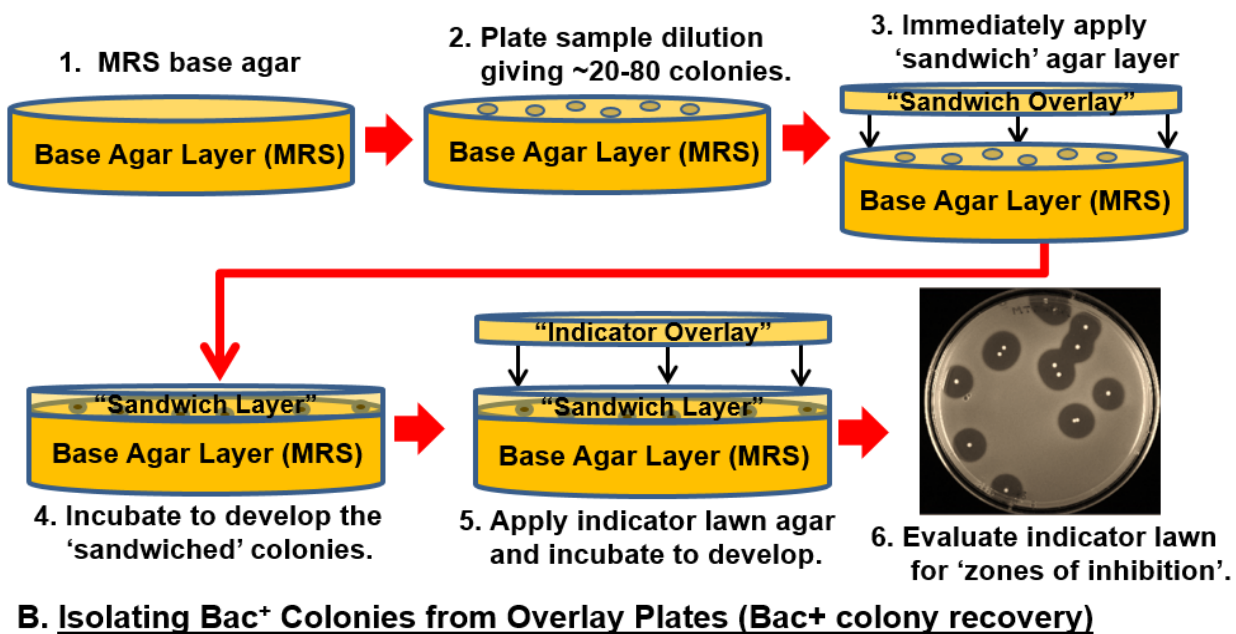

('Flip' the agar of the plate showing inhibition zones into its cover)

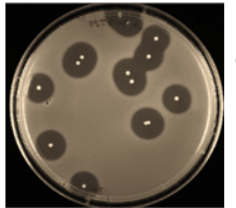

1. Flip the 3 agar layers into the inverted petri plate cover.

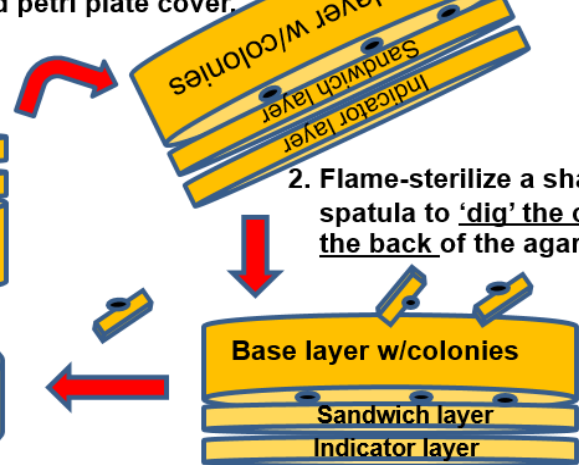

3. Streak flipped colony onto new MRS agar plate in order to 'purify' the colony (it could be contaminated with indicator cells or cells from other colonies).

C. Confirming and Purifying $\mathrm{Bac}^{+}$Isolate (patch-plate Bac+ confirmation).
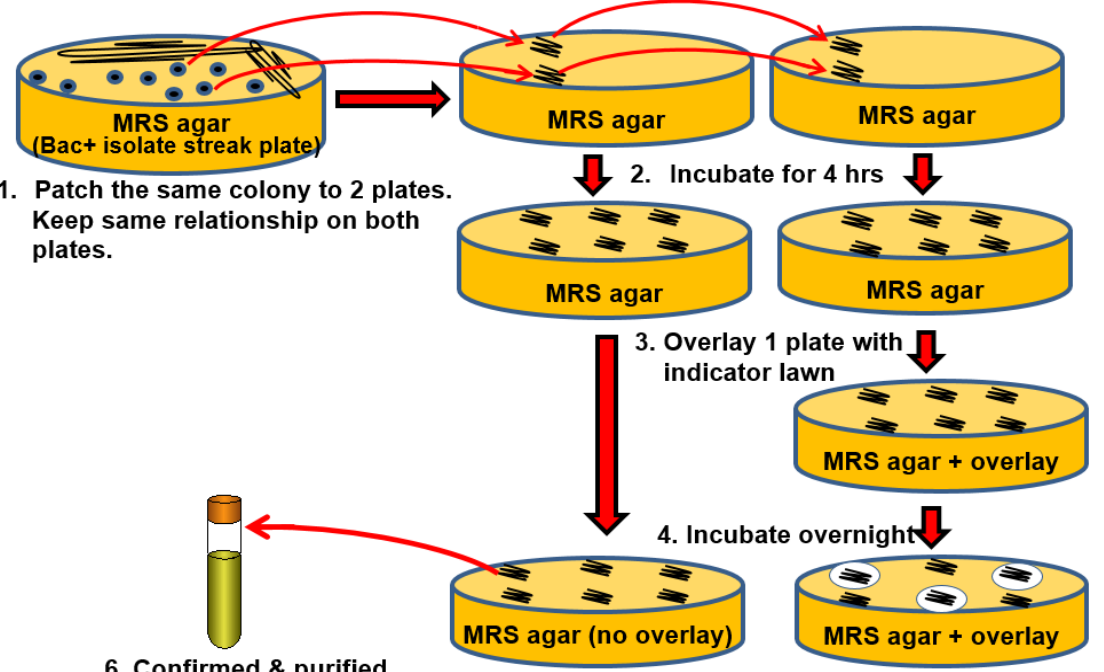

6. Confirmed \& purified $\mathrm{Bac}^{+}$culture.
5. Choose confirmed Bac+ from non-overlaid plate to inoculate culture tube.

Figure 1. Various protocols used in this study. Panel A, colony overlay assay (deferred antagonism) to identify $\mathrm{Bac}^{+}$colonies by the sandwich-overlay technique. Panel $\mathbf{B}$, isolation of $\mathrm{Bac}^{+}$colonies from sandwich overlay plates. Panel $\mathbf{C}$, the double patch plate method for purification and confirmation of $\mathrm{Bac}^{+}$colonies and generation of the stock culture. 


\subsection{Extraction of Total Bacterial DNA}

Prior to extraction of DNA, the $\mathrm{Bac}^{+}$isolates were inoculated into MRS broth and incubated at $30{ }^{\circ} \mathrm{C}$ for $16 \mathrm{~h}$. DNA was recovered from cell pellets of $1-\mathrm{mL}$ of cells by the bead-beating and ice-shaking procedure of Coton and Coton [14] and then stored at $-20{ }^{\circ} \mathrm{C}$ until needed. The concentration of DNA was measured using a NanoDrop ${ }^{\circledR}$ ND-1000 spectrophotometer (Thermo Scientific, Wilmington, DE, USA).

\subsection{Identification of Isolates by $16 S$ rRNA Gene Amplification, Sequencing, and Analysis}

The identification of $\mathrm{Bac}^{+}$bacteria was determined using PCR amplification with universal 16S ribosomal RNA primers 515F (5'-GTGCCAGCMGCCGCGGTAA-3') and 1391R (5'-GACGGGCGGTGTGTRCA3') as described by Turner et al. [15]. Thermal cycling was performed using a PTC-200 Peltier Thermal Cycler (MJ Research/Bio-Rad Laboratories, Hercules, CA, USA) as described previously [16]: initial denaturation at $95{ }^{\circ} \mathrm{C}$ for $4 \mathrm{~min}$, followed by 30 cycles of $94{ }^{\circ} \mathrm{C}$ for $1 \mathrm{~min}$ (denaturation), $60{ }^{\circ} \mathrm{C}$ for $45 \mathrm{~s}$ (annealing), $72{ }^{\circ} \mathrm{C}$ for $1 \mathrm{~min}$ (extension), followed by a final extension cycle at $72{ }^{\circ} \mathrm{C}$ for $4 \mathrm{~min}$, and a final hold at $4{ }^{\circ} \mathrm{C}$. Amplimers of $16 \mathrm{~S}$ rRNA genes were purified using the GenCatch ${ }^{\mathrm{TM}}$ Advanced PCR Extraction Kit (Epoch Life Sciences, Missouri City, TX, USA) according to the manufacturer's recommendations and eluted DNA was stored at $-20{ }^{\circ} \mathrm{C}$ until needed. Purified DNA was submitted to the Dept. of Biochemistry and Molecular Biology "DNA Core Facility" (Oklahoma State University) for sequencing using an automated DNA sequencer via "BigDye ${ }^{\text {TM" }}$ (Life Technologies, Grand Island, NY, USA)-terminated reactions analyzed on an ABI Model 3700 DNA Analyzer. ABI sequence files were analyzed using MEGA5 (The Biodesign Institute, Tempe, AZ, USA) [17] by cutting out 5' and 3' regions of high background noise. Consensus sequences were identified using NCBI's Nucleotide BLAST and then compiled together and aligned to create a maximum likelihood phylogenetic tree using MEGA 6 [18].

\section{Results}

\subsection{Isolation of $\mathrm{Bac}^{+}$Strains of $L A B$}

In this study, our objectives were to identify bacteriocinogenic LAB indigenous to retail foods and animal sources that were inhibitory to L. monocytogenes. $\mathrm{Bac}^{+}$bacteria were isolated from 23 of 170 retail food samples (14\% occurrence) and from 11 of 110 (10\%) animal-related sources (Table 1). Inhibitory activity was deemed to be the result of bacteriocin activity as there was no evidence of inhibition against L. monocytogenes due to bacteriophage, acid, or hydrogen peroxide, and protease treatment effectively demonstrated the protein nature of the active agent by hydrolysis of bacteriocin proteins that resulted in the subsequent loss of activity. 
Table 1. Bacteriocin-producing strains isolated or used in this study.

\begin{tabular}{|c|c|c|}
\hline Organism & Strain & Source/Reference \\
\hline Enterococcus faecium & $326 \mathrm{~F}$ & This study; bovine fecal sample \\
\hline Enterococcus faecium & FS97-2 & Vegetable [9] \\
\hline Enterococcus faecium & JCP B-5 & This study; pork sausage \\
\hline Enterococcus faecium & JCP M-2 & This study; pork sausage \\
\hline Enterococcus faecium & Thyme 2 & This study; thyme \\
\hline Enterococcus faecium & Thyme 3 & This study; thyme \\
\hline Enterococcus faecium & Milk 5 & This study; raw milk \\
\hline Enterococcus faecium & JCP-9 & This study; pork sausage \\
\hline Enterococcus faecium & Milk 12 & This study; raw milk \\
\hline Enterococcus faecium & Pop 4 & This study; dog feces \\
\hline Enterococcus faecium & FS56-1 & Mushrooms [9] \\
\hline Enterococcus durans & FS707 & This study; bovine fecal sample \\
\hline Enterococcus hirae & $323 \mathrm{~F}$ & This study; bovine fecal sample \\
\hline Enterococcus hirae & 323 RL1 & This study; bovine rumen fluid \\
\hline Enterococcus hirae & $341 \mathrm{FA}$ & This study; bovine fecal sample \\
\hline Enterococcus thailandicus & RP-1 & Raw pork [5] \\
\hline Enterococcus thailandicus & FS92 & Raw pork [9] \\
\hline Enterococcus faecalis & BJ-12 & Muriana culture collection \\
\hline Enterococcus faecalis & BJ-13 & Muriana culture collection \\
\hline Enterococcus faecalis & $\mathrm{BJ}-27$ & Muriana culture collection \\
\hline Carnobacterium maltaromaticum & LGBF-1 & This study; ground beef \\
\hline Carnobacterium maltaromaticum & GBF-1 & This study; ground beef \\
\hline Carnobacterium maltaromaticum & COG-1 & This study; collard greens \\
\hline Carnobacterium maltaromaticum & COG-2 & This study; collard greens \\
\hline Carnobacterium maltaromaticum & CHW-1 & This study; chicken wings \\
\hline Carnobacterium maltaromaticum & TOF-1 & This study; tofu \\
\hline Carnobacterium maltaromaticum & GPK-1 & This study; ground pork \\
\hline Carnobacterium maltaromaticum & GAC-1 & This study; ground chuck \\
\hline Carnobacterium maltaromaticum & GAC-2 & This study; ground chuck \\
\hline Pediococcus acidilactici & Bac3 & Ground turkey [5] \\
\hline Pediococcus acidilactici & FS707 S4 & This study; bovine fecal sample \\
\hline Lactobacillus ingluviei & FS60 & Cheese [9] \\
\hline Lactobacillus curvatus & BJ-5 & Muriana culture collection \\
\hline Lactobacillus curvatus & BJ-18 & Muriana culture collection \\
\hline Lactobacillus curvatus & $\mathrm{BJ}-21$ & Muriana culture collection \\
\hline Lactobacillus curvatus & BEEF 2L-1 & This study; ground beef \\
\hline Lactobacillus curvatus & BEEF 3 & This study; ground beef \\
\hline
\end{tabular}


Table 1. Cont.

\begin{tabular}{ccc}
\hline Organism & Strain & Source/Reference \\
\hline Lactobacillus curvatus & FS36-1 & Ground beef [9] \\
Lactobacillus curvatus & FS44-B & Ground pork [9] \\
Lactobacillus curvatus & FS47 & Ground beef [9] \\
Lactobacillus curvatus & FS80-2 & Muriana culture collection \\
Lactobacillus sakei & FS707 S1 & This study; bovine fecal sample \\
Leuconostoc mesenteroides & BFS-1 & This study; breakfast sausage \\
Staphylococcus gallolyticus & 707RS & This study; bovine rumen fluid \\
Staphylococcus gallolyticus & 341RL & This study; bovine rumen fluid \\
Lactococcus lactis & BJ-23 & Muriana culture collection \\
Lactococcus lactis & FL-1 & This study; lettuce (foxy) \\
Lactococcus lactis & FL S-1 & This study; lettuce (foxy) \\
Lactococcus lactis & FS91-1 & Fruit [9] \\
Lactococcus lactis & FS95 & Vegetables [9] \\
Lactococcus lactis & FS162 & Muriana culture collection \\
Lactococcus lactis & ASPG-1 & This study; asparagus \\
Lactococcus lactis & PJP-1 & This study; peppers \\
Lactococcus lactis & RDSH-1 & This study; radish (red) \\
Lactococcus lactis & SL-1 & This study; shredded lettuce \\
Lactococcus lactis & YO-1 & This study; yellow onion \\
Lactococcus lactis & SP-1 & This study; sweet potato \\
Lactococcus lactis & RD & This study; radish \\
Lactococcus lactis & GBN-1 & This study; green beans \\
Lactococcus lactis & BSP & This study; bean sprouts \\
Serratia plymuthica & POT-1 & This study; Russet Potato \\
Serratia ficaria & CCEL-1 & This study; Chinese celery \\
\hline
\end{tabular}

Enterococcus spp. represented the largest group of organisms and were often associated with animal-related sources, and En. faecium along with Lactococcus lactis comprised our largest phylogenetic groups (Table 1). Lactococcus lactis were obtained from the largest variety of sources, including green beans, radish, sweet potato, yellow onion, shredded lettuce, jalapeno peppers, asparagus, whole lettuce, and bean sprouts (Table 1). Lactobacillus curvatus isolates were obtained only from ground beef and, as psychrotrophs, they can grow well at refrigeration temperatures leading to shortened shelf life and spoilage. The sole Leuconostoc mesenteroides isolate was obtained from breakfast sausage. Carnobacterium maltaromaticum isolates were obtained from ground beef, collard greens, chicken wings, tofu, ground pork, and ground Angus chuck. Enterococcus faecium isolates were obtained from thyme herbs and pork sausage. The Serratia plymuthica isolate was obtained from russet potatoes while the Serratia ficaria isolate was obtained from Chinese celery. Although 25 samples were tested, no Bac ${ }^{+}$ LAB were isolated from fresh fruit in the current study. 


\subsection{Differentiation of Bacterial Isolates}

Newly-isolated $\mathrm{Bac}^{+}$bacteria spanned 6 different bacterial genera of lactic acid bacteria including Lactococcus, Carnobacterium, Enterococcus, Lactobacillus, Leuconostoc, and Pediococcus (Table 1). Similar $\mathrm{Bac}^{+}$bacteria from the same food sample were differentiated from each other by some type of distinguishing characteristics in order to minimize repeat isolations of the same organism. One method of differentiating $\mathrm{Bac}^{+}$strains is by inhibitory patterns against themselves; $\mathrm{Bac}^{+}$strains are not inhibitory to themselves because of bacteriocin immunity genes. For instance, Carnobacterium maltaromaticum COG-1 (indicator) was inhibited by C. maltaromaticum COG-2 (spotted culture), but not inhibited by its own spotting, proving that they are two different strains. This type of result only proves anything if one strain inhibits the other, or both inhibit each other, but provides no conclusive answer if neither inhibits the other as they could either be the same strain or conversely, simply insensitive to each other's bacteriocin. In the latter case, differences of inhibitory spectra involving other strains may be used to distinguish $\mathrm{Bac}^{+}$strains as was observed with Lb. curvatus Beef 2L-1 and Beef 3 whereby Beef 2L-1 was inhibited by En. faecalis BJ-13 but Beef 3 was not. Other differentiations were based on sequence analysis of bacteriocin structural gene sequences. For instance, En. faecium Thyme 2 possessed one enterocin structural gene (ent $\mathrm{A})$ while En. faecium Thyme 3 possessed two (ent $\mathrm{A}$, ent $\mathrm{B})$; similar differences were observed for En. hirae 343F (entA, mr10AB, munA) vs. En. hirae $323 \mathrm{RL} 1$ (entA, mr10AB), and En. faecalis BJ-12 (entA), En.faecalis BJ-13 (bacA), and En.faecalis BJ-27 as described recently by Henning et al. [16].

\subsection{Inhibition of Foodborne Pathogens}

The predominant primary indicator organism during this study was L. monocytogenes and an abundant supply of $\mathrm{Bac}^{+} \mathrm{LAB}$ capable of inhibiting L. monocytogenes were isolated (Table 1; Figure 2A). Other organisms were also used as "secondary indicators" once the $\mathrm{Bac}^{+}$isolates were obtained against L. monocytogenes. Although this approach was met with limited success, we were able to find some isolates capable of inhibiting Staphylococcus aureus ATCC 12600 (Figure 2B). However, no isolates were found that were inhibitory to E. coli O157:H7 or Salmonella Typhimurium using this secondary approach. A few food samples were tested directly with Salmonella as a primary indicator screen leading to the isolation of Serratia ficaria CCEL-1 that inhibited Salmonella Typhimurium (Figure 2C). When the Serratia strains were tested on other organisms, they were also found to inhibit S. aureus ATCC 12600 (Figure 2C), En. faecalis, and L. monocytogenes (Table 2). 

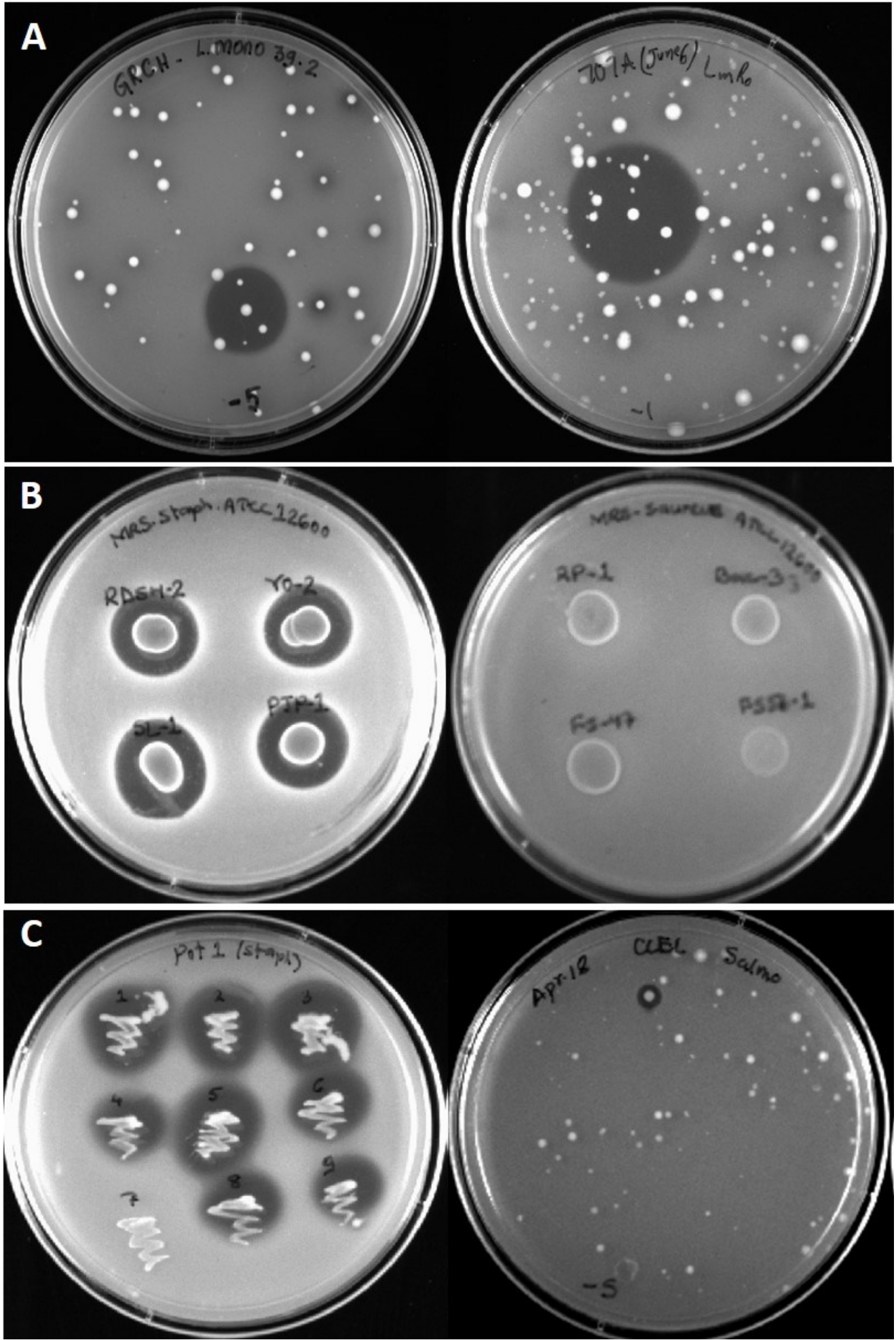

Figure 2. Bacteriocin inhibition zones from overlaid producer colonies, deferred antagonism spots, or patch-plate isolations. Panel A, representative bacteriocin inhibition zones obtained with "sandwich overlay" plates of food enrichment samples overlaid with Listeria monocytogenes 39-2 indicator lawns. Panel B, deferred antagonism assay of culture spots overlaid with Staphylococcus aureus ATCC 12600. Panel C, patch plate of Serratia plymuthica POT-1 (left) overlaid with S. aureus ATCC 12600 and an inhibition zone from Serratia ficaria CCEL-1 (right) against Salmonella Typhimurium H3380 used as a primary indicator screen. 
Table 2. Inhibitory activity elicited by select $\mathrm{Bac}^{+}$strains against various foodborne pathogens.

\begin{tabular}{|c|c|c|c|c|}
\hline $\begin{array}{c}\text { Select Bacteriocin-Producing } \\
\text { Strains } \\
\end{array}$ & $\begin{array}{c}\text { Listeria } \\
\text { monocytogenes 39-2 }\end{array}$ & $\begin{array}{c}\text { Staphylococcus } \\
\text { aureus ATCC } 12600\end{array}$ & $\begin{array}{l}\text { Staphylococcus } \\
\text { aureus ISP } 178 \\
\end{array}$ & $\begin{array}{c}\text { Enterococcus faecalis } \\
\text { ATCC } 19433 \\
\end{array}$ \\
\hline Enterococcus thailandicus RP-1 & ++1 & - & - & $\mathrm{ND}^{2}$ \\
\hline Enterococcus faecium FS56-1 & ++++ & - & - & ND \\
\hline Enterococcus durans FS707 & ++++ & - & - & ++ \\
\hline Lactobacillus curvatus FS47 & ++++ & - & - & - \\
\hline Lactobacillus curvatus Beef3 & ++++ & - & - & - \\
\hline Lactobacillus curvatus FS44-B & +++ & - & - & - \\
\hline Lactococcus lactis BSP & +++ & ++ & ++ & + \\
\hline Lactococcus lactis SL1 & ++ & +++ & +++ & + \\
\hline Lactococcus lactis RDSH-1 & +++ & +++ & +++ & + \\
\hline Lactococcus lactis ASPG-1 & +++ & +++ & +++ & + \\
\hline Lactococcus lactis YO-1 & +++ & +++ & +++ & + \\
\hline Lactococcus lactis FLS1 & + & + & + & + \\
\hline Lactococcus lactis GBN-1 & ++ & + & + & + \\
\hline Lactococcus lactis PJP-1 & +++ & +++ & +++ & + \\
\hline Pediococcus acidilactici Bac3 & ++++ & - & - & ND \\
\hline Serratia plymuthica POT-1 ${ }^{3}$ & ++ & ++ & ++ & + \\
\hline Serratia ficaria CCEL-1 ${ }^{3}$ & + & + & + & + \\
\hline
\end{tabular}

\subsection{Phylogenetic Analysis}

Bacteria were identified by DNA sequence analysis of amplimers obtained from PCR reactions performed with universal primers for $16 \mathrm{~S}$ rRNA genes. Some $\mathrm{Bac}^{+}$strains were included for 16S rRNA identification that were isolated previously and identified incorrectly by phenotypic methods [9] or API $50 \mathrm{CH}$ panels [5], demonstrating the accuracy of this method of identification over phenotypic methods. For instance, En. faecium FS56-1 and FS97-2 were incorrectly identified as Lactococcus lactis using a variety of phenotypic characteristics [9] and later, along with En. thailandicus FS92 and RP-1, were again incorrectly confirmed as Lc. lactis using API 50CH panels [5]. The phylogenetic distribution of $\mathrm{Bac}^{+}$organisms based on 16S rRNA partial sequences from this study are shown in Figure 3 as a Maximum Likelihood Tree of sequence relatedness constructed from 61 nucleotide sequences using the MEGA 6 genetic analysis software.

\section{Discussion}

The analysis of $\mathrm{Bac}^{+}$bacteria from common market foods and samples from animal sources in this study implicates a variety of bacterial genera with the ability to produce bacteriocins including some genera that are not members of the lactic acid bacteria. The actual prevalence of $\mathrm{Bac}^{+}$bacterial strains in retail foods are likely much higher than what we have identified because our findings represent only those that were inhibitory to our primary indicator strain. Select indicator strains may not be susceptible to all $\mathrm{Bac}^{+}$organisms, some of which may show up as $\mathrm{Bac}^{-}$against "the wrong" given indicator 
organism. The burden of using all the indicator organisms in this study as primary indicator screens prevented as thorough an isolation rate as was obtained with $L$. monocytogenes, and retesting $\mathrm{Bac}^{+}$ isolates against secondary indicator organisms has its limitations. Also, the use of MRS broth/agar media limits the detection to those organisms that can grow on it, providing a selective preference (in this study) for lactic acid bacteria.

Several modifications were accommodated in this study over prior studies; notably all isolates were subjected to $16 \mathrm{~S}$ rRNA sequencing and identification. This provided more accurate sequence-based identification and demonstrated that some previously isolated strains were incorrectly identified as lactococci using less stringent identification methods. Similar results have been observed in other comparisons of 16S rRNA sequence-based identification compared to phenotypic test kits [19,20].

Enrichment schemes were also altered from 24 to 4-h enrichments when we questioned whether lactococci that are known to grow to $10^{10} \mathrm{cfu} / \mathrm{mL}$ in culture media may predominate in enriched food samples over other $\mathrm{Bac}^{+}$bacteria that may not grow to similarly high levels, given that the screening process is based on plating schemes examining higher end dilutions. Due to the high prevalence of Lactococcus lactis, we reduced enrichment times to $4 \mathrm{~h}$ to provide an opportunity to isolate other organisms that may not grow to the level of Lactococcus. Also, the use of buffered agar media during isolation of $\mathrm{Bac}^{+} \mathrm{LAB}$ against acid-sensitive pathogenic indicator organisms eliminated the likelihood of false-positives from inhibition zones due to acid inhibition.

In prior studies, a sensitive lactic acid indicator organism (i.e., Lb. delbrueckii 4797) was often used as a primary indicator of $\mathrm{Bac}^{+}$bacteria that were then used to test on organisms of interest (i.e., L. monocytogenes). This approach was stopped because of the possibility that the initial isolation may have restricted the spectrum of activity because the initial selection was limited to that showing inhibition towards the LAB (Figure 2B). In this study, L. monocytogenes was used directly as a primary indicator strain and numerous isolated were obtained that were inhibitory to Listeria. However, a similar approach using other organisms (i.e., Salmonella, E. coli $\mathrm{O} 157: \mathrm{H} 7$, etc.) as primary indicator organisms would similarly benefit from improved detection frequencies than to examine them by a secondary screening regimen. This is evidenced by the detection of an isolate inhibitory to Salmonella when Salmonella was used as a primary susceptible indicator organism to directly screen for inhibitory colonies (Figure 2C). Despite the use of various additional organisms via a secondary screening approach, we did identify inhibition to other pathogens (Table 2) that may well suit our interest in examining bacteriocins that may have different modes-of-action with the purpose of combining them in food applications.

\section{Conclusions}

This work extends our knowledge of the ubiquitous distribution of $\mathrm{Bac}^{+}$bacteria in foods and provides further argument that consumers may be ingesting $\mathrm{Bac}^{+}$bacteria or their byproducts on foods they already eat. Despite the heavy emphasis on food safety in the past decade whereby antimicrobials are added/sprayed onto raw or processed meats, vegetables, and produce for the interest of "pathogen reduction", there does not seem to be a scarcity of $\mathrm{Bac}^{+}$bacteria on foods, providing researchers a broad array of antimicrobials for potential use as food preservatives. The organisms and bacteriocins described 
in this work are currently being examined in greater detail to accommodate their application as antimicrobials against L. monocytogenes in food applications.

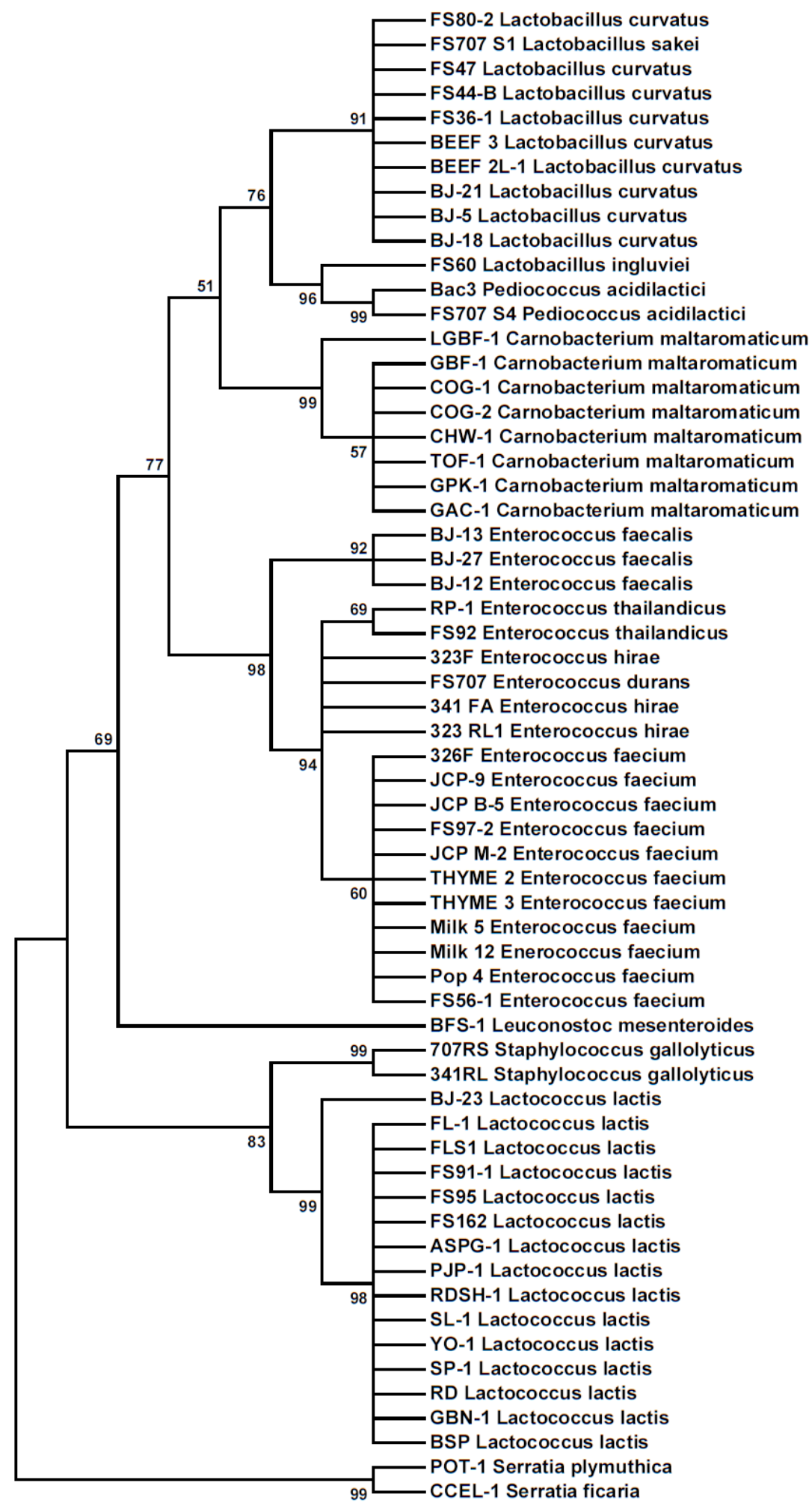

Figure 3. Phylogenetic tree of $16 \mathrm{~S}$ rRNA partial sequences from $\mathrm{Bac}^{+}$bacteria by the Maximum Likelihood method. The phylogenetic relationship was inferred using the Tamura-Nei model [21] showing the tree with the highest log likelihood (-2162.4232). The percentage of trees in which the associated taxa clustered together is shown next to the branches. 


\section{Acknowledgments}

This paper was funded in part by an OCAST-OARS grant (\#AR12-049), Nutrition Physiology Co. (Guyman, OK, USA), the Department of Animal Science, the R.M. Kerr Food \& Ag Products Center (Oklahoma State University), and the Oklahoma Agricultural Experiment Station (Hatch Project \#OKL02885).

\section{Author Contributions}

The isolation of organisms from various foods and animal sources was equally contributed by the entire group of authors. Chris Henning additionally performed 16S rRNA analyses and identity determinations of the organisms and wrote the initial draft of the manuscript. Peter Muriana was the advisor on record for Chris Henning, PI of the grant from which funding was obtained to perform the work, and editor of the submitted manuscript.

\section{Conflicts of Interest}

The authors declare no conflict of interest.

\section{References}

1. Nes, I.F.; Diep, D.B.; Holo, H. Bacteriocin diversity in Streptococcus and Enterococcus. J. Bacteriol. 2006, 189, 1189-1198.

2. Nes, I.F.; Johnsborg, O. Exploration of antimicrobial potential in lab by genomics. Curr. Opin. Biotechnol. 2004, 15, 100-104.

3. Casaus, P.; Nilsen, T.; Cintas, L.M.; Nes, I.F.; Hernandez, P.E.; Holo, H. Enterocin B, a new bacteriocin from enterococcus faecium T136 which can act synergistically with enterocin A. Microbiology 1997, 143 Pt 7, 2287-2294.

4. Knoll, C.; Divol, B.; du Toit, M. Genetic screening of lactic acid bacteria of oenological origin for bacteriocin-encoding genes. Food Microbiol. 2008, 25, 983-991.

5. Macwana, S.J.; Muriana, P.M. A "bacteriocin pcr array" for identification of bacteriocin-related structural genes in lactic acid bacteria. J. Microbiol. Methods 2012, 88, 197-204.

6. De Jong, A.; van Hijum, S.A.; Bijlsma, J.J.; Kok, J.; Kuipers, O.P. Bagel: A web-based bacteriocin genome mining tool. Nucleic Acids Res. 2006, 34, W273-W279.

7. Cleveland, J.; Montville, T.J.; Nes, I.F.; Chikindas, M.L. Bacteriocins: Safe, natural antimicrobials for food preservation. Int. J. Food Microbiol. 2001, 71, 1-20.

8. Macwana, S.; Muriana, P.M. Spontaneous bacteriocin resistance in listeria monocytogenes as a susceptibility screen for identifying different mechanisms of resistance and modes of action by bacteriocins of lactic acid bacteria. J. Microbiol. Methods 2012, 88, 7-13.

9. Garver, K.I.; Muriana, P.M. Detection, identification and characterization of bacteriocin-producing lactic-acid bacteria from retail food-products. Int. J. Food Microbiol. 1993, 19, 241-258.

10. Muriana, P.M.; Klaenhammer, T.R. Purification and partial characterization of lactacin-F, a bacteriocin produced by lactobacillus-acidophilus-11088. Appl. Environ. Microbiol. 1991, 57, 114-121. 
11. Garver, K.I.; Muriana, P.M. Purification and partial amino-acid-sequence of curvaticin FS47, a heat-stable bacteriocin produced by lactobacillus-curvatus FS47. Appl. Environ. Microbiol. 1994, 60, 2191-2195.

12. Muriana, P.M. Bacteriocins for control of Listeria spp. in food. J. Food Protect. 1996, Supplement, 54-63.

13. Muriana, P.M.; Klaenhammer, T.R. Conjugal transfer of plasmid-encoded determinants for bacteriocin production and immunity in lactobacillus-acidophilus-88. Appl. Environ. Microbiol. 1987, 53, 553-560.

14. Coton, E.; Coton, M. Multiplex pcr for colony direct detection of gram-positive histamine- and tyramine-producing bacteria. J. Microbiol. Methods 2005, 63, 296-304.

15. Turner, S.; Pryer, K.M.; Miao, V.P.W.; Palmer, J.D. Investigating deep phylogenetic relationships among cyanobacteria and plastids by small subunit RRNA sequence analysis1. J. Eukaryot. Microbiol. 1999, 46, 327-338.

16. Henning, C.; Gautam, D.; Muriana, P. Identification of Multiple Bacteriocins in Enterococcus spp. Using an Enterococcus-Specific Bacteriocin PCR Array. Microorganisms 2015, 3, 1-16.

17. Tamura, K.; Peterson, D.; Peterson, N.; Stecher, G.; Nei, M.; Kumar, S. MEGA5: Molecular evolutionary genetics analysis using maximum likelihood, evolutionary distance, and maximum parsimony methods. Mol. Biol. Evol. 2011, 28, 2731-2739.

18. Tamura, K.; Stecher, G.; Peterson, D.; Filipski, A.; Kumar, S. MEGA6: Molecular evolutionary genetics analysis version 6.0. Mol. Biol. Evol. 2013, 30, 2725-2729.

19. Bosshard, P.P.; Zbinden, R.; Abels, S.; Böddinghaus, B.; Altwegg, M.; Böttger, E.C. 16s RRNA gene sequencing $v s$. the API 20 NE system and the VITEK 2 ID-GNB card for identification of nonfermenting Gram-negative bacteria in the clinical laboratory. J. Clin. Microbiol. 2006, 44, 1359-1366.

20. Kulwichit, W.; Nilgate, S.; Chatsuwan, T.; Krajiw, S.; Unhasuta, C.; Chongthaleong, A. Accuracies of leuconostoc phenotypic identification: A comparison of API systems and conventional phenotypic assays. BMC Infect. Dis. 2007, 7, 69.

21. Tamura, K.; Nei, M. Estimation of the number of nucleotide substitutions in the control region of mitochondrial DNA in humans and chimpanzees. Mol. Biol. Evol. 1993, 10, 512-526.

(C) 2015 by the authors; licensee MDPI, Basel, Switzerland. This article is an open access article distributed under the terms and conditions of the Creative Commons Attribution license (http://creativecommons.org/licenses/by/4.0/). 